\title{
X-DR (DRUG RESISTANT) TYPHOID FEVER IN CHILDREN.
}

1. MBBS, FCPS

Senior Registrar Paediatrics

Children Hospital and ICH,

Faisalabad.

2. MBBS, FCPS

Assistant Professor

Children Hospital and ICH,

Faisalabad.

3. MBBS, FCPS

Assistant Professor

Children Hospital and $\mathrm{ICH}$, Faisalabad.

4. MBBS, FCPS

Senior Registrar Paediatrics Children Hospital and $\mathrm{ICH}$,

Faisalabad.

5. MBBS, FCPS

Senior Registrar Paediatrics Children Hospital and ICH, Faisalabad.

6. MBBS, FCPS

Professor Paediatrics

Faisalabad Medical University.

Correspondence Address:

Dr. Muhammad Sohail

136-B Sheikh Colony,

Jhang Road Faisalabad.

arshadsohail66@gmail.com

Article received on:

$11 / 02 / 2020$

Accepted for publication:

$20 / 04 / 2020$

\section{INTRODUCTION}

Enteric fever caused by Salmonella enterica serovar typhi (S.Typhi) is serious and occasionally fatal disease, more prevalent in developing countries attributed to poor sanitation facilities and lack of clean drinking water supply. Approximately 21.6 million people are infected by S.Typhi yearly leading to around two hundred thousands deaths with more than $90 \%$ burden of morbidity and mortality shared by Asian countries. ${ }^{1,2}$ India and Pakistan are ranked first and second in Enteric fever prevalence respectively. ${ }^{3}$

Drug resistance is emerging as a great problem in managing cases of enteric fever leading to increasing cost of treatment, morbidity and complications. ${ }^{3,4,5}$ It started in early 70 's. $^{5}$
Over past 2 decades, emergence of MDR (chloramphenicol, amoxicillin, TMP) strains has necessitated use of fluroquinolones as drug of choice with cephalosporins as alternative. ${ }^{6}$ But recent reports of XDR (chloramphenicol, amoxicillin, TMP, fluroquinolones and ceftriaxone) strains of Salmonella in areas of Sindh (Pakistan) have been alarming. ${ }^{7,9,10}$ International Surveillance has also identified XDR strains in patients in UK, USA and Canada with all of them having travelled to Pakistan in recent past. 8,9

Pakistan health authorities have reported an outbreak of extensively (XDR) typhoid fever that begin in Hyderabad district of Sindh province in November, 2016. ${ }^{11}$ Since then, number of patients with XDR typhoid fever are remarkably increasing. 
We think that XDR typhoid fever is not confined to Sindh Province only and is spreading all over the Pakistan, we have observed a surge of typhoid fever cases in our setup.

We are conducting this study with objective to evaluate antibiotic sensitivity pattern in patients presenting with clinical suspicion of enteric fever at Children hospital, Faisalabad which will help us to formulate management guidelines for drug resistant patients and to stress on need of vaccination against S.Typhi.

\section{MATERIAL \& METHODS}

This was Prospective, consecutive sampling conducted for 6 months. Study was conducted from June 2019 to November 2019 at Children Hospital and Institute of Child Health, Faisalabad.

\section{Inclusion Criteria}

- Patients having febrile illness more than five days and there is no other observed cause of fever.

\section{Exclusion Criteria}

- Age less than one year and more than sixteen year.

- Patients having other comorbidities were also excluded from study.

After admitting the patients blood culture and sensitivity, CBC and other relevant investigations were carried out to exclude other causes of fever like Malaria, Dengue, UTI etc. Those patients who received antibiotics for more than 5 days their blood culture was not sent. Blood samples were cultured on blood agar and MacConkey agar plates. After identification of organism as Salmonella Typhi, antibiotic susceptibility testing was done by disk diffusion technique and zones of inhibition were interpreted according to Clinical and Laboratory Standards Institute (CLSI) guidelines. Isolates were tested for ampicillin, co-trimoxazole, ceftriaxone, cefixime, chloramphenicol, ciprofloxacin, amikacin, azithromycin and meropenem susceptibility. We were able to send culture of 31 patients only due to one or more reason. All patients were given intravenous ceftriaxone $75 \mathrm{mg} / \mathrm{kg} /$ day in two divided doses empirically after sending blood culture. The patients whose culture sent were later treated according to sensitivity pattern if they have not responded to empirical therapy. However, culture negative and all those patients whose culture were not sent and who did not respond to intravenous ceftriaxone after 7 days were switched to meropenem or azithromycin depending upon susceptibility patterns. No complication was observed in any patient. All patients were treated successfully.

Frequencies and percentages were calculated for gender and XDR isolates. Mean was calculated for age distribution of culture positive patients.

\section{RESULTS}

We studied 60 patients admitted with clinical suspicion of enteric fever from June 2019 November 2019.Out of these 60 patients, 37 patients (61.6\%) were males and $23(38.4 \%)$ were females. Among them 47 (78.3\%) patients were urban residents while 6 (10\%) and 7 (11.6\%) were from peri-urban and rural areas respectively. Maximum cases were admitted during July to September. Most common presentation was fever (100\%), abdominal pain (68.33\%), vomiting (60\%) followed by Diarrhea (25\%) (Table-I) Common signs seen were tachycardia (75\%), pallor (25\%), Hepatosplenomegaly (16.6\%), coated tongue (8.3\%), Hepatomegaly (10\%) and Splenomegaly (1.6\%) (Table-II) .

Out of 31 patients, $14(45 \%)$ were culture positive and 17 (55\%) were culture negative. Among 14 culture positive patients, 12 patients (85.7\%) turned out to be XDR strains of Salmonella typhi, only sensitive to Meropenem and Azithromycin. One patient $(7.1 \%)$ was sensitive to Meropenem only and one patient (7.1\%) to Amikacin and Co-trimoxazole only (Table-III) Mean age of culture positive patients was 7.2 years (TableIV). All these 14 patients were empirically treated with ceftriaxone. Those who didn't responded to empirical therapy switched to Meropenem or azithromycin depending upon susceptibility patterns.

Of the remaining 46 culture negative patients 
(including 29 patients whose cultures were not sent), 33(71.7\%) patients responded to ceftriaxone alone. Out of remaining 13 patients, 10 patients $(76.9 \%)$ responded to azithromycin and $3(23.1 \%)$ patients responded to meropenem only. None of these 46 patients developed any complication and were discharged.

Overall sensitivity/response rate of 60 patients to various antibiotics was observed as, ceftriaxone 33/60(55\%), meropenem 16/60(26.6\%), azithromycin 10/60(16.6\%) and amikacin $1 / 60(1.6 \%)$.

\begin{tabular}{|l|c|}
\hline \multicolumn{1}{|c|}{ Symptoms } & Percentage \\
\hline Fever & $100 \%$ \\
\hline Abdominal pain & $68.33 \%$ \\
\hline Vomiting & $60 \%$ \\
\hline Diarrhea & $25 \%$ \\
\hline Anorexia & $13.33 \%$ \\
\hline Constipation & $1.6 \%$ \\
\hline
\end{tabular}

Table-I. Symptoms observed in patients

\begin{tabular}{|l|c|}
\hline \multicolumn{1}{|c|}{ Signs } & Percentage \\
\hline Tachycardia & $75 \%$ \\
\hline Pallor & $25 \%$ \\
\hline Hepatosplenomegaly & $16.6 \%$ \\
\hline Hepatomegaly & $10 \%$ \\
\hline Coated Tongue & $8.3 \%$ \\
\hline Splenomegaly & $1.6 \%$ \\
\hline
\end{tabular}

Table-II. Signs observed in patients

\begin{tabular}{|l|c|c|}
\hline \multicolumn{1}{|c|}{ Antibiotic } & $\begin{array}{c}\text { Number } \\
(\mathbf{n = 1 4 )}\end{array}$ & Percentage \\
\hline Meropenem & 14 & $100 \%$ \\
\hline Azithromycin & 13 & $92.8 \%$ \\
\hline Ceftriaxone, Cefixime & 0 & $0 \%$ \\
\hline Ampicillin, Ciprofloxacin & 0 & $0 \%$ \\
\hline Chloramphenicol & 0 & $0 \%$ \\
\hline Amikacin, Co-trimoxazole & 1 & $7.1 \%$ \\
\hline
\end{tabular}

Table-III. Antibiotic sensitivity pattern of Salmonella Typhi

\begin{tabular}{|l|c|c|}
\hline $\begin{array}{l}\text { Age at the Time } \\
\text { of Presentation }\end{array}$ & $\begin{array}{c}\text { Frequency of } \\
\text { Patients }\end{array}$ & $\begin{array}{c}\text { Percentage of } \\
\text { Patients }\end{array}$ \\
\hline$<5$ years & 5 & $35.7 \%$ \\
\hline 5 to 10years & 4 & $28.5 \%$ \\
\hline 10 to 15years & 5 & $35.7 \%$ \\
\hline \multicolumn{2}{|c|}{ Table-IV. Age distribution of patients with XDR } \\
Salmonella Typhi $(\mathbf{n = 1 4 )}$ \\
\hline
\end{tabular}

\begin{tabular}{|c|c|c|c|c|}
\hline \multicolumn{2}{|l|}{ Months } & $\begin{array}{l}\text { No. of Cases } \\
\quad(n=60)\end{array}$ & \multicolumn{2}{|c|}{ Percentage } \\
\hline \multicolumn{2}{|l|}{ June } & 08 & \multicolumn{2}{|c|}{$13.3 \%$} \\
\hline \multicolumn{2}{|l|}{ July } & 14 & \multicolumn{2}{|r|}{$23.3 \%$} \\
\hline \multicolumn{2}{|l|}{ August } & 14 & \multicolumn{2}{|c|}{$23.3 \%$} \\
\hline \multicolumn{2}{|l|}{ September } & 11 & \multicolumn{2}{|c|}{$18.3 \%$} \\
\hline \multicolumn{2}{|l|}{ October } & 08 & \multicolumn{2}{|c|}{$13.3 \%$} \\
\hline \multicolumn{2}{|l|}{ November } & 05 & \multicolumn{2}{|r|}{$8.3 \%$} \\
\hline \multicolumn{5}{|c|}{ Table-V. Month wise distribution of cases } \\
\hline Month & $\begin{array}{l}\text { Number of } \\
\text { Patients } \\
\text { Admitted } \\
(n=60)\end{array}$ & $\begin{array}{c}\text { Number } \\
\text { of Blood } \\
\text { Cultures } \\
\text { sent } \\
(n=31)\end{array}$ & $\begin{array}{l}\text { Positive } \\
\text { Blood } \\
\text { Cultures } \\
(n=14)\end{array}$ & $\begin{array}{c}\text { Percentage } \\
\text { of Positive } \\
\text { Blood } \\
\text { Cultures }\end{array}$ \\
\hline June & 08 & 01 & 01 & $100 \%$ \\
\hline July & 14 & 06 & 03 & $50 \%$ \\
\hline August & 14 & 08 & 02 & $25 \%$ \\
\hline September & 11 & 05 & 02 & $40 \%$ \\
\hline October & 08 & 07 & 05 & $71.4 \%$ \\
\hline November & 05 & 04 & 01 & $25 \%$ \\
\hline Total & 60 & 31 & 14 & $45.1 \%$ \\
\hline
\end{tabular}

\section{DISCUSSION}

Most of the studies already done on typhoid fever includes age group of 5 to 15 years. However, in studies from Bangladesh and India higher trends are seen in children younger than 5 years. ${ }^{12}$ So, we included age group 1 to 15 years and found that the maximum children affected were in age groups less than 5 years and greater than 10 years. Perhaps it is difficult to maintain hygiene in these age groups as less than 5 years demand continue surveillance by elders and age group greater than 10 years are school going and have easy access to food stuff at school canteens.

Male to female ratio is $1.6: 1$ and this is very similar to a study done in Bangladesh. ${ }^{13}$ Greater percentage of patients belong to urban areas ${ }^{12}$ and only a small percentage was found resident of rural areas indicating poor hygienic conditions and sanitation of our urban areas, inviting attention of health authorities to promote public awareness and guide government officials to work on this. 
Maximum cases were admitted during July to September. We know this period coincides with moon-soon season and increase in house fly population, hence facilitating feco-oral transmission. Same phenomena was observed in most of studies done in Asia. ${ }^{3,14}$

Most common presentation was fever (100\%), abdominal pain (68.33\%), vomiting (60\%) followed by Diarrhea (25\%) which was very similar to a study done by Habte, L., Tadesse, E., Ferede, G., et al Ethiopia at University of Gondar, Ethiopia. ${ }^{15}$

Common signs seen were tachycardia (75\%), pallor (25\%), Hepatosplenomegaly (16.6\%), coated tongue (8.3\%), Hepatomegaly (10\%) and Splenomegaly (1.6\%). ${ }^{14}$

In this study we were able to send culture of $51 \%$ of patients (31 cases) only. Out of them $45 \%$ of patients (14 cases) were found culture positive. Our culture positivity rate was very high as compare to studies done in other parts of Asia and Pakistan that showed a range of 5 to $33.1 \% .^{3,16}$ In an analysis, based on antibiotic susceptibility from 2012-2014, prevalence of MDR salmonella typhi was $52 \%$, fluoroquinolone resistance was $90 \%$ and there was no cephalosporin resistance. ${ }^{17}$ But the recent trends seen in studies from 2015-2019, showed a decline in MDR strains and rising trends of resistance against cefixime and ceftriaxone. . $^{18,19}$ In our study there were $100 \%$ MDR strains and only $7.1 \%$ were sensitive to amikacin and cotrimoxazole and no isolate was found sensitive to ceftriaxone, cefixime, ampicillin or ciprofloxacin.

We have reported only 14 culture positive patients. As this number is very small to make any solid conclusion. So, continue surveillance should be in place to find the actual burden of XDR typhoid fever in Faisalabad. For this, we may need collaboration with other medical institutes of Faisalabad for collection of data regarding XDR typhoid fever. Considering the reports from Hyderabad, Sindh, we recommend local district administration and health authorities to launch an awareness campaign regarding sanitation, good hygiene, use of safe water and mass vaccination of children with conjugated vaccine against typhoid which has already initiated in district Hyderabad. Along with these, injudicious use of antibiotics should be banned and it can be safely prevented by sensitising general practitioners and clinicians on the rational use of antimicrobials for typhoid fever.

\section{CONCLUSION}

Emergence and spread of XDR typhoid fever is on the rising trend. Surveillance studies are required at all levels for risk stratification and control of this disease. Our study also signifies the role of preventive measures, better health care facilities, antibiotic stewardship and vaccination, at a national level to restrict this menace.

\section{Copyright(C) 20 Apr, 2020.}

\section{REFERENCES}

1. Ali MK, Sultana S. Antimicrobial sensitivity pattern of Salmonella Typhi in children. Bangladesh J. Med Sci 2016; 15:416-8.

2. Nagshetty K, Channappa ST, Gaddad SM. Antimicobial susceptibility of Salmonella Typhi in India. $J$ infect Dev Ctries 2009; 4:070-3.

3. Ochial RL, Acosta CJ, Denovaro-Holliday M, Baiqing D, Bhattacharya SK, Agtini MD, et al. A study of typhoid fever in five Asian countries. Disease burden and implications for controls. Bull World health Organ 2008; 86:260-8.

4. Hasan B,Nahar SG, Akter L, Saleh AA. Antimicrobila sensitivity pattern of Salmonella typhi isolates from blood culture in a referral hospital. Bangladesh $\mathrm{J}$ Med Microbial 2011; 5:16-20.

5. Harish BN, Menezes GA. Antibiotic resistance in typhoid Salmonellae. Indian J Med Microbiol 2011; 29:223.

6. Kleigmann M, Stantor F,Joseph W, Schor F, Editor Behram E. Infectious diseases. Nelson Textbook of Paediatrics (South Asian Edition) 21 $1^{\text {st }}$ ed. Reed Elsevier India; 2019.

7. Klemm EJ, Shakoor S, Page AJ, et al.: Emergence of an extensively drug-resistant Salmonella enterica serovar Typhi clone harboring a promiscuous plasmid encoding resistance to fluoroquinolones and third-generation cephalosporins. MBio. 2018, 9:10.1128/mBio.00105-18. 
8. Wong W, Rawahi HA, Patel S, et al.: The first Canadian pediatric case of extensively drug-resistant Salmonella Typhi originating from an outbreak in Pakistan and its implication for empiric antimicrobial choices. ID Cases. 2019, 15:e00492.

9. Typhoid fever - Islamic Republic of Pakistan. (2018). Accessed: April 1, 2019: https://www.who.int/csr/ don/27-december-2018-typhoid-pakistan/en/.

10. Saeed N, Usman M, Khan EA. An Overview of Extensively Drug-resistant Salmonella Typhi from a Tertiary Care Hospital in Pakistan. Cureus. 2019 Sep;11(9).

11. R. K. Muhammad, H.S. Syed, B. Zaheer, A. I. Syed, Extensively drug resistant typhoid fever in Pakistan, March 2019 Vol. 19(3), P 242-243.

12. Naheed A, Ram P.K, Brooks W.A, Burden of typhoid and Paratyphoid fever in a density populated urban community. Dhaka, Bangladesh; Int J Infect Dis 2010; 14:e93-9.

13. Sattar AA, Chowdhury MS, Yusuf MA, Jesmin S, Ara $S$, Islam MB. Age and Gender Difference of Typhoid Fever among Paediatric Patients Attended at a Tertiary Care Hospital in Bangladesh. Bangladesh Journal of Infectious Diseases. 2016;3(2):36-9.
14. R.C. Sudharshan, Clinical profile and antibiotic sensitivity pattern of typhoid fever in patients admitted to paediatric ward in a rural Teaching Hospital. Int J Med Res Health Sci. 2014; 3(2): 245-249.

15. Habte L, Tadesse E, Ferede G, Amsalu A. Typhoid fever: clinical presentation and associated factors in febrile patients visiting Shashemene Referral Hospital, southern Ethiopia. BMC Research Notes. 2018 Dec 1;11(1):605.

16. L. S. Ghulam, H. Zahid, [...], and A. Aatera, Antimicrobial susceptibility patterns of salmonella species in Southern Pakistan; Cureus. 2019 Apr; 11(4): e4379.

17. Qamar FN, Yousafzai MT, Sultana S. A retrospective study of laboratory-based enteric fever surveillance, Pakistan, 2012-2014, J Infects Dis 2018; 218:S201-5.

18. Das JK, Hasan R, Zafar A. Trends, associations, and antimicrobial resistance of Salmonella typhi and paratyphi in Pakistan Am J Trop Med Hyg 2018; 99:4854.

19. S. A. Altaf, S. Anum, T. Ambar, Antimicrobial resistance trends of Typhoidal Salmonellae in Southern Pakistan, Rawal Med J: (2019); Vol.44(1):7-10.

\begin{tabular}{|c|c|c|c|}
\hline \multicolumn{4}{|c|}{ AUTHORSHIP AND CONTRIBUTION DECLARATION } \\
\hline Sr. \# & Author(s) Full Name & Contribution to the paper & Author(s) Signature \\
\hline 1 & Muhammad Sohail & 1st Author & Sol and \\
\hline 2 & Zahid Mahmood Anjum & 2nd Author & \\
\hline 3 & Jaweeria Masood & 3rd Author & eeria \\
\hline 4 & Iram lqbal & 4th Author & \\
\hline 5 & Jawaria Khalid & 5th Author & Jamaria \\
\hline 6 & Hina Ayesha & 6th Author & 1, \\
\hline
\end{tabular}

